\title{
CONF-9507163-.1
}

\section{Reaching Minority, Female and Disadvantaged Students}

\author{
C. Edward Oliver \\ H. Richard Hicks \\ Barbara G. Summers \\ Computing, Robotics, and Education \\ Oak Ridge National Laboratory* \\ P. O. Box 2008 \\ Oak Ridge, TN 37831
}

To be presented at the American in the Age of Information: A Forum on Federal Information and

Communications R\&D, Bethesda, MD, July 6-7, 1995;

to be published in the Proceedings.

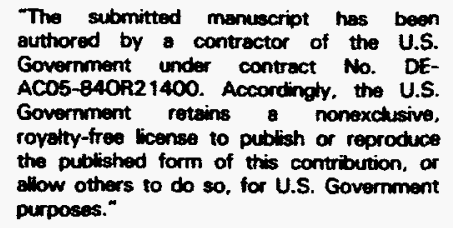

DISCLAIMER

This report was prepared as an account of work sponsored by an agency of the United States Government. Neither the United States Government nor any agency thereof, nor any of their employees, makes any warranty, express or implied, or assumes any legal liability or responsibility for the accuracy, completeness, or usefulness of any information, apparatus, product, or process disclosed, or represents that its use would not infringe privately owned rights. Reference herein to any specific commercial product, process, or service by trade name, trademark, manufacturer, or otherwise does not necessarily constitute or imply its endorsement, recommendation, or favoring by the United States Government or any agency thereof. The views and opinions of authors expressed herein do not necessarily state or reflect those of the United States Government or any agency thereof.

* Managed by Lockheed Martin Energy Systems, Inc., under contract Number DE-AC05-84OR21400 with the U.S. Department of Energy 


\section{DISCLAIMER}

Portions of this document may be illegible in electronic image products. Images are produced from the best available original document. 
Reaching Minority, Female and Disadvantaged Students

\author{
C. Edward Oliver \\ H. Richard Hicks \\ Barbara G. Summers \\ Oak Ridge National Laboratory*
}

\begin{abstract}
Adventures in Supercomputing (AiS) is an innovative educational outreach program to address the shortfall in human resources in science and engineering. The program has been funded since 1992 as part of the Department of Encrgy's High Performance Computing and Communications Program. Supercomputers are used both as a magnet to draw students into science and engineering and as an enabling tool to assist them to explore simulations based on mathematical or physical models. The program presently involves 69 high schools and 5 middle schools in five states: Alabama, Colorado, Iowa, New Mexico, and Tennessee.
\end{abstract}

The primary goal of this program is to capture and cultivate the interest of minority, female, and disadvantaged students in science, mathematics, and computing. By improving the leachers' computer expertise and scientific knowledge through intense training, teachers are able to reach out confidently to this target group of students. An environment to support computing education for both students and teachers is strengthened during the year through continued technical support.

This paper will discuss methods of encouraging minorities, women, and disadvantaged students to become involved in the Adventures in Supercomputing program. It will share achievements of this diverse school population over the past years as these student engage in long term computational science projects. It will also share the assessment results showing the success of the program.

\section{School Selection}

In each of the 5 participating states, application forms are distributed to high schools. The applying schools must propose a team of at least two teachers. They must propose to teach one or more AiS year-long courses. They may also propose to integrate AiS material into existing classes and to form AiS clubs.

The application must propose how the tcacher team intends to attract minority, female, disadvantaged, and other students who are normally underrepresented in technical populations. In cases where the school does not have a large minority population, geographically isolated population, or population below the poverty level, it is expected that the teacher team will propose very specific means for attracting the target population.

Thc application also addresses the qualifications of the teacher team in presenting the AiS material to students. This includes computing and networking experience, as well as science teaching experience.

The completed applications are reviewed by a committee convened in each state. The intended result is the selection of schools where the target population will be reached, and where the teachers have shown the capability to present the AiS material.

\section{Program Elements}

The AiS program bas many elements. To understand the process of involving a diverse population, as well as the assessment results, it is important to have an overall view of the program.

Each AiS school is provided with teacher and student accounts on DOE parallel supercomputers, and direct access to the Internet at $56 \mathrm{kbps}$ or better. They are loaned four Macintosh computers which are loaded with the software to run telnet, ftp, Web browser, word processor, spreadsheet, communications package, database management system, and scientific visualization software. They are also loaned a color printer.

The program provides each school with continuing technical support, to prevent a software, hardware, or network problem from interfering with the progress of the class.

In the Summer following selection, the teacher reams attend a Summer Institute in their home 
state. The teachers are familiarized with all the hardware and software that will be in the school, as well as with exploring the Internet and using the parallel processor supercomputers.

In the Fall of the school year, teachers introduce their students to FORTRAN programming, scientific visualization, Internet exploration, finding mentors, and identifying a computational science project. Thc remainder of the year is focused on completing a project, which is undertaken by a single student, or teams of 2 to 4 students. The projects are presented at an Exposition in each AiS state, which is essentially a science fair, but for computational science projects. Completed projects are judged by a team of computational scientists, and the top entrants compete in the national AiS Exposition in Washington, DC.

\section{Essential Characteristics of AiS}

School must apply to participate in AiS. In so doing, they must make a number of commitments that will help insure their success.

Teachers teaching teachers at the Summer Institule provides credibility to the new AiS teachers who initially doubt that they can takc on this ambitious program.

The Summer Institute and the follow-up workshops provides the professional development that is essential to jump starting the teachers.

Teacher teams are essential to provide mutual support in the school, to marshal a diverse background, and to be a hedge against a teacher leaving an AiS school.

Student diversity is achieved by recruitment or by virtue of favorable demographics. AiS teachers arc mindful of all students getting a fair share of computer time.

The team projects require students to develop an ability for cooperative learning

Computers are for student use, not primarily for teacher use or for administrative use.

In most cases, AiS classes are multigrade, and often include return AiS students who may refine projects started in previous years. The more experienced students provide some guidance for the younger students.

The project and interactive nature of AiS requires the teachers to act as academic coaches, rather than lecturers.

AiS insures that the level of technology that the students have is reasonably commensurate with what is used today in research and business. This includes a direct network (non-modcm) connection, and emphasize the exchange of information over the Internet - rather than by CDROM or diskette.

An overall focus for the school year is provided by the projects that are prepared for the Spring Exposition. All of the AiS activities are aimed toward this goal.

Viewed as an experiment, it has been essential to incorporate an evaluation of AiS by a third party. This has bcen done by the Cenler for Children and Technology. The results are describes in the Evaluation section.

The project orientation provides considerable focus for the year's activities, and, along with the use of modern technology, makes the Ais curriculum 'authentic', in the sense that their progress resembles the manner in which a real rescarch team would approach solving a problem. The processes that they go through to develop their projects, including forming tcams and leaming many tools to carry out their trade, are all elements of authentic education.

Although AiS did not set out to drive systcmic change, many of the characteristics of AiS have conspired to produce systemic change. Perhaps, this is a better approach than trying to abstractly determine what steps one should take to promote systemic change. In AiS, systemic change is a natural consequence.

\section{Observations}

Small school districts have had more success at implementing the AiS program. They seem to have more flexibility in absorbing the signifjcant changes that $\mathrm{AiS}$ requires.

Intemet access is useful at all schools for providing a world view, and it is particularly 
significant at schools which are geographically isolated.

Three years into the program, we find that we are able to decrease the level of technical support. For example, in Tennessee, we are able to go from two graduate students to one part-time AiS teacher for technical support for 15 schools. Many of the AiS teachers can solve a majority of their technical problems. This level of support might be higher if there were less uniformity in the technology used.

Preparing to teach AiS requires extra time from most teachers. It might be advisable to incorporate a provision in the school application that guarantees the participating teachers an appropriate level of release time.

In some cases, we have provided a laptop computer for teachers to take home. Since the classroom machines are normally fully used by students, this can be the only means for teachers to learm.

Students are largely motivated by the fact that they find AiS to be fun, not because they sce it as a career move. At the high school age, the pleasure derived from participating in AiS contributes to its success, and to further recruitment of students.

In AiS parent \& community involvement is teacher-led. No attempt has been made as yet to institutionalize this aspect of the program. In some instances, the community has provided considcrable matching equipment.

The impact of AiS on teachers and students is dramatic. For many, it truly changes their lives.

\section{Evaluation Results [1]}

The evaluation of the AiS program was based on final project presentalion. Performance-based assessment measures were used to assess video taped student presentations, based on a standard format. Each vidco presentation was scored using established performance assessment criteria.

The two formal central findings are:

"Over half of the AiS students demonstrated a mastery of their computational arcas of inquiry. These students effectively integrated knowledge across the conceptual and technical dimensions of their work by successfully applying computational techniques to a well-defined set of questions."

"There was no evidence of a gap in achievement based either on student scx or race, suggesting that the AiS approach to learning is effectively overcoming sex-and race-based performance gaps that remain evident in numerous indicators of math and science performance."

\section{Conclusions Regarding Diversity}

The AiS recruitment process tends to result in AiS classes, on average, mirroring the national demographics. However, the same can be said, in many cases, for required high school classes.

The important distinction of AiS is the fact that the outcomes is independent of race and sex. Because of the complexity of any classroom situation, we have not definitively identified which characteristics of AiS provide this result.

\section{References}

1. Honey, Margaret, McMillan Katie, Tsikalas, Kallen, and Grimaldi, Clareann, Adventures in Supercomputing 1993 - 1994 Evaluation, Final Report, Center for Children and Technology (CCT) Reports Issue 1, January 1995.

$* * * * *$

\section{Edward Oliver}

Dr. C. Edward Oliver received his Ph.D. in Mathematics in 1969 from the University of Alabama. He is an Associate Director of Oak Ridge National Laboratory.

\section{H. Richard Hicks}

Dr. H. Richard Hicks received his Ph.D. in Physics in 1971 from the University of Mlinois. Hicks is Director of the Office of Computing and Network Management at Oak Ridge National Laboratory.

\section{Barbara G. Summers}


Barbara G. Summers received her Masters in Curriculum Development in 1980 from Tennessee Technology University. She taught math, science and computer programming for 24 years in Wartburg, Tennessee. She is presently coordinating the Adventures in Supercomputing program for Tennessec through the office of Science Education at Oak Ridge National Laboratory.

* Managed by Lockheed Martin Energy Systems, Inc., under contract DE-AC05-840R21400 with the U.S. Department of Energy. 